\title{
INCIDÊNCIAS DE MANIFESTAÇÕES PATOLÓGICAS CAUSADAS PELA UMIDADE EM EDIFICAÇÕES HOSPITALARES: ESTUDO DE CASO EM UM MUNICÍPIO DE SANTA CATARINA
}

\author{
PILLON, FELIPE \\ Engenheiro Civil \\ Universidade do Vale do Itajaí \\ SC; Brasil \\ pillonfelipe@hotmail.com \\ VENÂNCIO, CAROLINE \\ Engenheira Civil, phD \\ Universidade do Vale do Itajaí \\ SC; Brasil \\ caroline.venancio@univali.br
}

\author{
CARVALHO, RAFAELLA GRANGEIRO DE \\ Estudante - Engenharia Civil \\ Universidade do Vale do Itajaí \\ $\mathrm{SC}$; Brasil \\ rafaella_g_c_@hotmail.com
}

\section{RESUMO}

Os ambientes hospitalares devem ser limpos e ausentes de microrganismos que poderiam afetar a saúde dos usuários da edificação. A umidade nestes ambientes favorece a proliferação de microrganismos e por isto a necessidade da avaliação das manifestações mais incidentes em edifícios hospitalares. O trabalho objetiva a avaliação da incidência das principais manifestações patológicas encontradas em edificações hospitalares no município do estado de Santa Catarina (Brasil). Ao todo, oito edificações hospitalares foram visitadas e a inspeção foi realizada por meio visual, termografia e registro das manifestações com a utilização de câmera fotográfica. Todas as manifestações ocasionadas por transporte de umidade ou relacionadas à umidade na edificação foram avaliadas e assim, de acordo com a maior incidência de algumas manifestações, objetiva-se o traçado de um plano de ações corretivas e de maior urgência nestes ambientes. Por meio de uma análise estatística foi possível verificar que as infiltrações por água de precipitação, ascensão de água do solo por capilaridade e a falta de circulação de ar entre os ambientes despontaram como a principal fonte das manifestações patológicas na maioria dos locais avaliados. E, em alguns locais específicos, a análise visual por meio da câmera termográfica tornou-se essencial para uma correta avaliação da manifestação patológica.

Palavras-chave: estudo de caso, umidade, edificios hospitalares.

\section{ABSTRACT}

Hospital environments should be clean and free of microorganisms that could affect the health of building users. The humidity in these environments favors the proliferation of microorganisms and therefore the need to evaluate the most incident manifestations in hospital buildings. This study aims to evaluate the incidence of the main pathological manifestations found in hospital buildings in the city of Santa Catarina (Brazil). In all, eight hospital buildings were visited, and the inspection was carried out visually, using thermography and recording the manifestations using a photographic camera. All manifestations caused by moisture transport or related to humidity in the building were evaluated and thus, according to the higher incidence of some manifestations, the objective is to outline a corrective and urgent action plan in these environments. Through a statistical analysis it was possible to verify that the infiltration by precipitation water, rise of ground water by capillarity and the lack of air circulation between the environments emerged as the main source of pathological manifestations in most of the evaluated sites. And in some specific locations, visual analysis through the thermographic camera has become essential for a correct assessment of pathological manifestation. Keywords: case study, humidity, hospital buildings.

\section{INTRODUÇÃO}

A patologia na construção civil se dedica ao estudo de problemas das edificações e suas alterações estruturais e funcionais causadas nas mesmas. Esses defeitos podem ser adquiridos durante a execução da obra devido a empregos inadequados dos materiais e métodos, na elaboração do projeto, ou também adquiridos ao longo de sua vida útil (FRANÇA, et al., 2010). 
A Engenharia Civil é uma área do conhecimento humano que acontece uma constante evolução e modificação. Mudanças tecnológicas ocorrem nos materiais utilizados para as construções, nos desenvolvimentos dos projetos, com novos programas de computadores para análise, cálculo e detalhamento de estruturas. A relação entre as manifestações patológicas e a qualidade da construção está fortemente relacionada com a qualidade da execução. Na maioria dos casos, essas manifestações ocorrerão devido a defeitos relacionados aos materiais e componentes utilizados no processo construtivo, bem como problemas relacionados à umidade (SOUZA; RIPPER, 2009).

A umidade na construção civil é um problema de grande importância e que se apresenta com grande frequência nas edificações. Os problemas relacionados à umidade podem ser de difícil correção devido a uma análise falha da causa e da origem da manifestação. A umidade se faz presente em inúmeros elementos que fazem parte de uma edificação, como por exemplo: paredes, fachadas, platibandas e na própria estrutura de concreto armado (PEREZ, 1988).

A utilização da termografia na construção civil não só se estende à análise de infiltrações nas edificações em concreto armado, onde uma análise apenas visual seria ineficaz, como também, torna-se eficaz para uma caracterização térmica de bloco de concreto (CARUANA et al., 2014).

Os problemas relacionados à umidade na edificação, sempre trazem grande desconforto e preocupação, além de degradar muito rapidamente a construção. Em edifícios hospitalares as manifestações patológicas decorrentes de infiltração de água propiciam ambientes insalubres e prejudicam a saúde dos usuários, bem como a sua recuperação nestes ambientes. As manifestações decorrentes de umidade nos elementos construtivos tendem a apresentar vários sintomas e muitas vezes uma infiltração de água pode ser causa ou origem de outra manifestação patológica, ou seja, que dela decorre. Neste sentido, o trabalho foi desenvolvido com o objetivo de avaliar as principais manifestações patológicas decorrentes da umidade em edifícios hospitalares em um município de Santa Catarina (Brasil) que se localiza a aproximadamente $72 \mathrm{~km}$ da capital, Florianópolis. Assim, possibilita-se um plano de ações mais assertivo aos edifícios, de acordo com as principais causas e origens das manifestações analisadas.

\section{MATERIAIS E MÉTODOS}

O estudo de caso consiste em métodos investigativos que descrevem situações precedentes, trazendo dados e produzindo um material descritivo que permite reinterpretações e releituras para novos estudos (ALVES, 2011). O método utilizado é o de pesquisa de campo, realizando-se um levantamento da incidência das manifestações patológicas de umidade em edifícios de saúde pública.

O projeto foi desenvolvido com base na coleta de informações das manifestações patológicas em oito edificações da área da saúde pública, de idades diferentes, sendo estas, Unidades Básicas de Saúde (UBS) do município. A coleta de dados foi realizada nos edifícios por meio de croquis, projetos e vistorias com inspeção visual, registo fotográfico e termografia. As edificações apresentaram como características principais a estrutura em concreto armado e paredes de alvenaria em blocos cerâmicos.

Iniciou-se a inspeção pelas fachadas das edificações, estendendo-se para: recepção, sala de emergência, corredores de acesso, quartos de internação, salas de consultas, salas de espera, banheiros, refeitórios e cozinhas. Nesse trabalho a vistoria se iniciou pela parte superior do edifício, quando havia mais de um pavimento, continuando em direção ao térreo. Cada ambiente de interesse foi vistoriado seguindo uma ordem estabelecida: dos fundos das edificações para a porta de entrada. Após a vistoria do interior do edifício, realizava-se, se necessário, o exame da parte externa da edificação, partindo de procedimentos análogos. Quando se fez necessário, realizou-se a inspeção aos edifícios e terrenos vizinhos, verificando suas condições e sua interferência na edificação do caso de estudo.

Efetuou-se um mapeamento dos problemas encontrados e estabelecido um plano de reforma para as manifestações patológicas encontradas, garantindo o uso e a qualidade das atividades desenvolvidas nos limites da edificação. Descreveram-se as causas e se definiram as possíveis soluções para que se tenha uma prevenção dos problemas relacionados com a umidade nestas edificações, garantindo menores gastos com manutenções ineficazes e muitas vezes, reformas desnecessárias.

Para esse trabalho foram geradas 934 imagens fotográficas e 120 imagens com a câmera termográfica. Dessa maneira, foram realizadas discussões e gráficos percentuais de cada tipo de manifestação encontrada, delimitando uma provável singularidade aos problemas causados/originados pela umidade. 


\section{RESULTADOS}

As UBS se localizavam entre 262 a 4291 metros do mar. A localização de cada edificação foi avaliada para a verificação de uma correlação ou não, das manifestações com a proximidade das edificações ao mar.

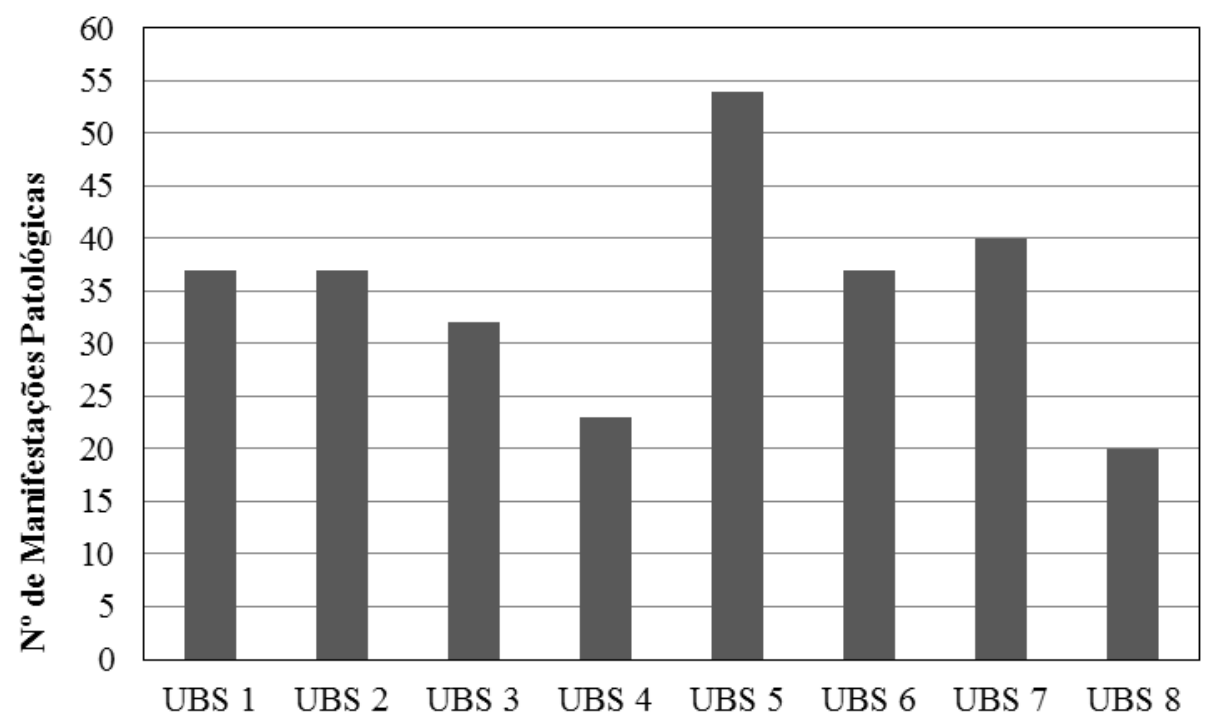

Figura 1: Número de manifestações patológicas encontradas nas UBS analisadas decorrentes da umidade nas edificações.

As UBS 2 e UBS 5 eram as edificações que estavam mais próxima do mar e a mais distante do mar, respectivamente. A Figura 1 demonstra que a maior proximidade da UBS 2 com o mar não resultou num maior número de manifestações patológicas relacionadas à umidade, na edificação.

As principais manifestações encontradas nas edificações foram manchas de umidade devido à absorção de água por capilaridade na alvenaria de vedação, eflorescências, vesículas, manchas e mofo nas pinturas. Alguns problemas visualizados na pintura, também se estendiam ao revestimento argamassado.

\subsection{Absorção de Água por Capilaridade}

Na Figura 2 foi possível identificar manifestações patológicas localizadas no pavimento térreo e decorrentes da absorção de água por capilaridade. Nestas manifestações patológicas por ascensão de água por capilaridade, a umidade é proveniente do solo e o problema geralmente decorre de uma má ou ausência da impermeabilização das vigas baldrame.

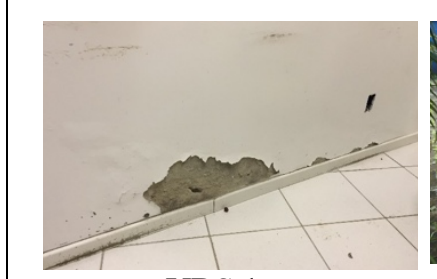

UBS 1

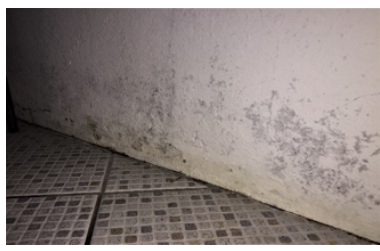

UBS 5

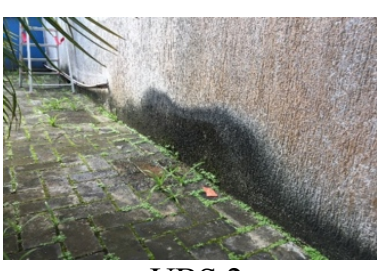

UBS 2

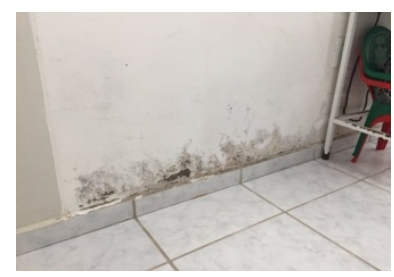

UBS 6

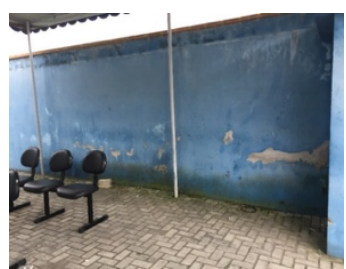

UBS 3

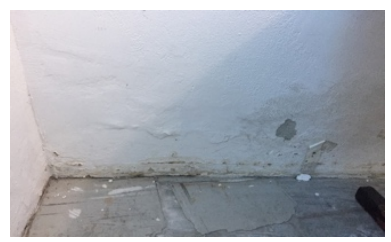

UBS 7

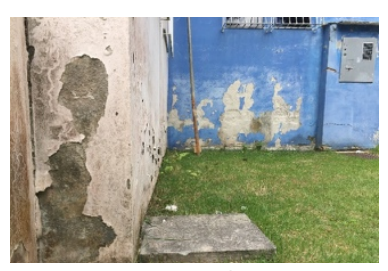

UBS 4

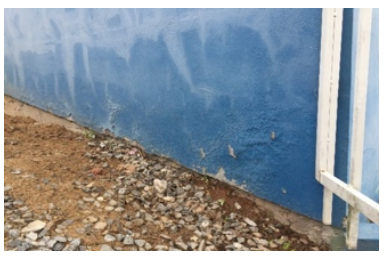

UBS 8

Figura 2: Manifestações patológicas encontradas nas UBS decorrentes da absorção de água por capilaridade. 


\subsection{Eflorescência}

Nas indicações da Figura 3 podem-se observar marcas esbranquiçadas de forma intensa, um acúmulo de sais entre o revestimento argamassado e pintura, originários de sais solúveis presentes nos materiais dos revestimentos argamassados e nos blocos cerâmicos.

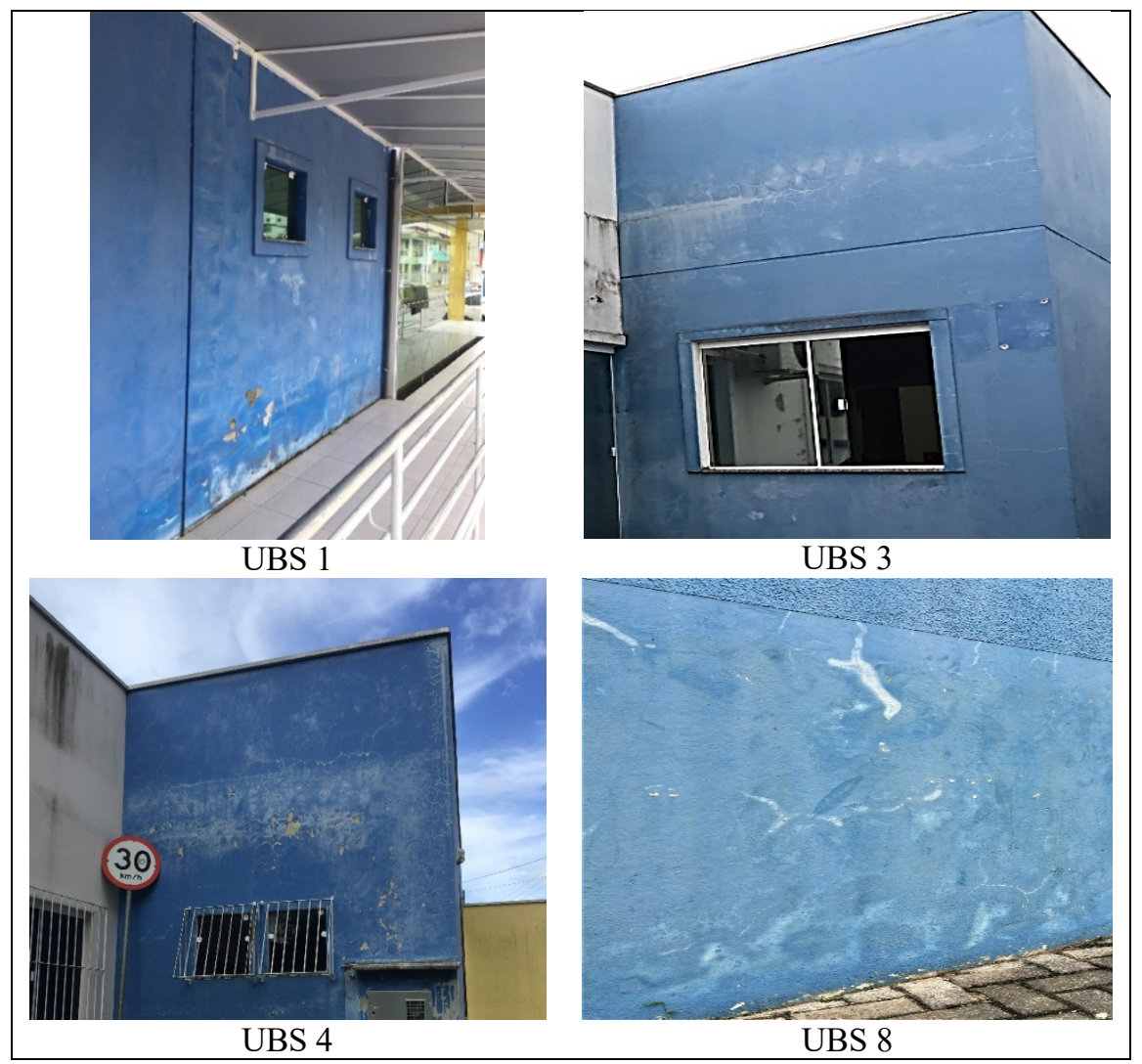

Figura 3: Manifestações patológicas de lixiviação que foram visualizadas na pintura das edificações.

As eflorescências foram encontradas em todas as UBS mas foram apresentados alguns casos mais relevantes, das UBS 1, 3, 4 e 8. Notou-se que os sais eram dissolvidos pela umidade oriunda do solo (absorção de água por capilaridade) e da cobertura da edificação. Durante a vistoria das UBS não se teve acesso à laje de cobertura para avaliar a presença, ausência ou a má execução da impermeabilização. No entanto, torna-se importante, além da execução da impermeabilização, a proteção do telhado com a disposição do sistema de captação da água da chuva (rufos e calhas).

\subsection{Vesículas}

As vesículas são decorrentes do processo de infiltração de água. As manifestações foram encontradas em paredes internas, mas de fechamento externo, apresentando em alguns casos, fissuras no lado de fora da edificação (Figura 4).

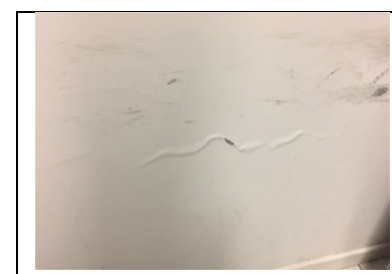

UBS 1

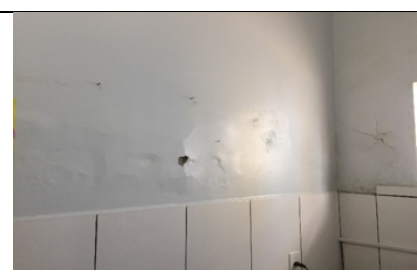

UBS 2

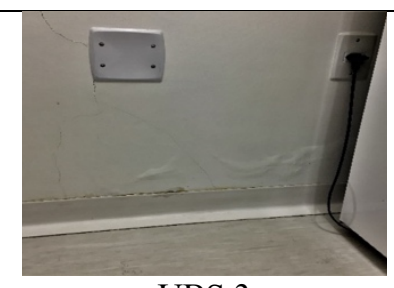

UBS 3

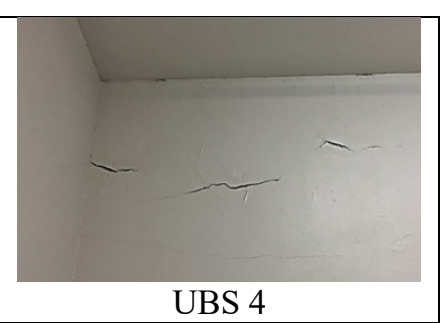




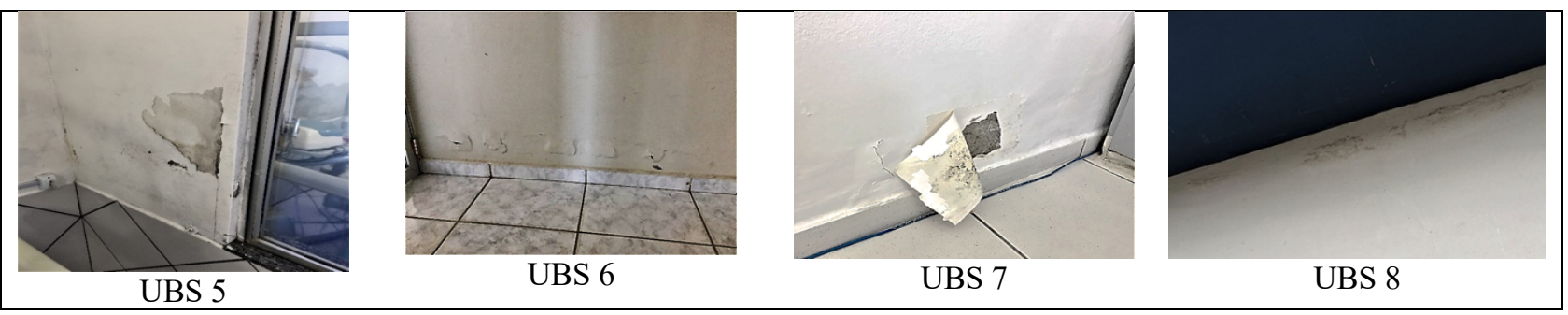

Figura 4: Vesículas (bolhas) encontradas na pintura das paredes das UBS decorrentes de umidade.

Como foi apresentado na Figura 4, as vesículas se apresentam na parte inferior das paredes, devido ao processo de infiltração de água por capilaridade e também na parte superior das paredes (UBS 2, 4 e 8).

Na UBS 2, verificou-se um caso muito comum e de grande erro de execução, a tentativa de eliminar a umidade dos ambientes com a colocação do revestimento cerâmico. O revestimento cerâmico não elimina a infiltração de água e as vesículas por acúmulo de água ocorrem acima do revestimento.

Na UBS 4, as vesículas aparecem juntamente a fissuras. Estas fissuras, por sua configuração podem ser decorrentes de variação térmica, uma vez que esta parede é de fechamento externo da edificação. Porém, alguns estudos e ensaios deveriam ser realizados para um correto diagnóstico.

E no caso da UBS 8, as vesículas são decorrentes de uma infiltração de água na parte superior da laje, uma vez que as vesículas se localizam no encontro de uma marquise (azul) e uma parede externa.

\subsection{Manchas}

As manchas de umidade foram muito recorrentes nas UBS e estão apresentadas na Figura 5. As manchas foram encontradas em paredes externas, faces externas e internas e em lajes.

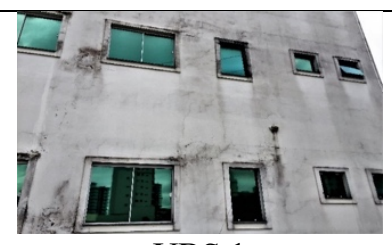

UBS 1

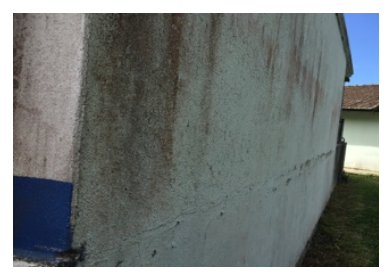

UBS 5

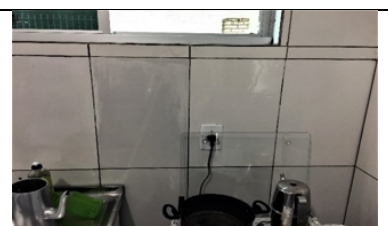

UBS 2

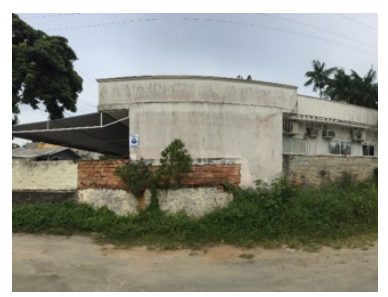

UBS 6

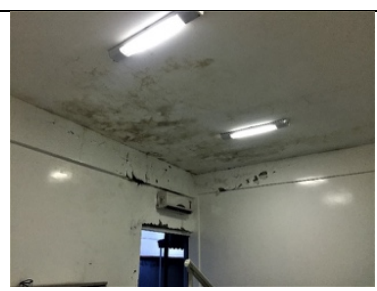

UBS 3

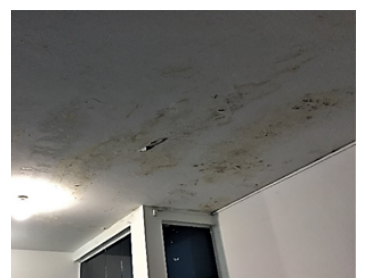

UBS 7

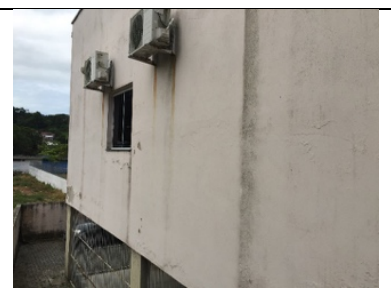

UBS 4

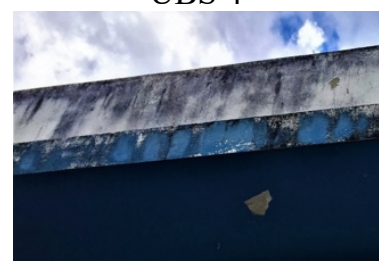

UBS 8

Figura 5: Vesículas (bolhas) encontradas na pintura das paredes das UBS decorrentes de umidade.

Algumas das manchas de umidade apresentadas na Figura 5 estão associadas a outras manifestações como mofo, bolor, empolamento, desplacamentos do revestimento cerâmico e pintura, corrosão de armadura, etc.

Esta é a grande dificuldade de apontar as principais causas e origens de uma mancha de umidade na pintura (UBS 1), no revestimento cerâmico (UBS 2), na alvenaria (UBS 6) ou na laje (UBS 7).

A mancha no revestimento cerâmico ocorreu devido a uma falha na estanqueidade de uma junta de dilatação, com ocorrência em todos os andares. Verificaram-se manchas de forma generalizada na parede (UBS 1, 4, 5 e 6 ) decorrente de infiltração de água (água da chuva) e seu escorrimento pela fachada. Estas paredes são de fechamento interno/externo, construídas com materiais de pouca qualidade e muito porosos. Além disto, também se observou a existência de falhas 
de execução nos cantos das janelas (parapeitos) e buracos na parede (decorrentes de instalações de ar condicionado ou outra alteração ocorrida sem o acompanhamento de profissional técnico adequado).

\subsection{Mofo}

Nas Figuras 2 e 5, anteriormente apresentadas, constatou-se a proliferação e ocorrência de mofo e bolor nas edificações das UBS avaliadas. Esse acúmulo de mofo ocorre por falta de circulação de ar em ambientes que estão sempre fechados, por falta de manutenção das juntas de dilatação nas edificações (ou má execução) e serviços executados de forma incorreta.

Bactérias e fungos são microrganismos capazes de criar uma película sobre a superfície dos revestimentos, desde que exista a presença constante de água neste ambiente, somado a condições ambientais propícias como temperatura e umidade. Dessa maneira, por intermédio de reações químicas, esses microrganismos propendem a solubilizar parte dos materiais onde estão alojados (revestimentos argamassados) consumindo o material ocasionando o a biodeterioração (SHIRAKAWA, et al., 1999).

\subsection{Análise termográfica}

Em todas as UBS, durante o processo de vistoria, fez-se o uso da câmera termográfica. No entanto, este instrumento de análise foi crucial para o estudo de alguns casos de manifestações encontradas na UBS 1. Observou-se entre a imagem digital e a térmica, (Figura 6) que onde ocorre um maior acúmulo de mofo, tem-se maior umidade, justificando a menor temperatura (azul) na imagem térmica. Com isso, a concentração de umidade ocasiona uma disagregação da argamassa ao longo do tempo. Na parte de baixo do detalhe construtivo e rodapé da parede, também há umidade, mas com menor intensidade. A origem dessa água infiltrada se deu por falha de vedação na junta de dilatação, verificada na parte superior da figura e indicada nas Figura 6 (por flechas).

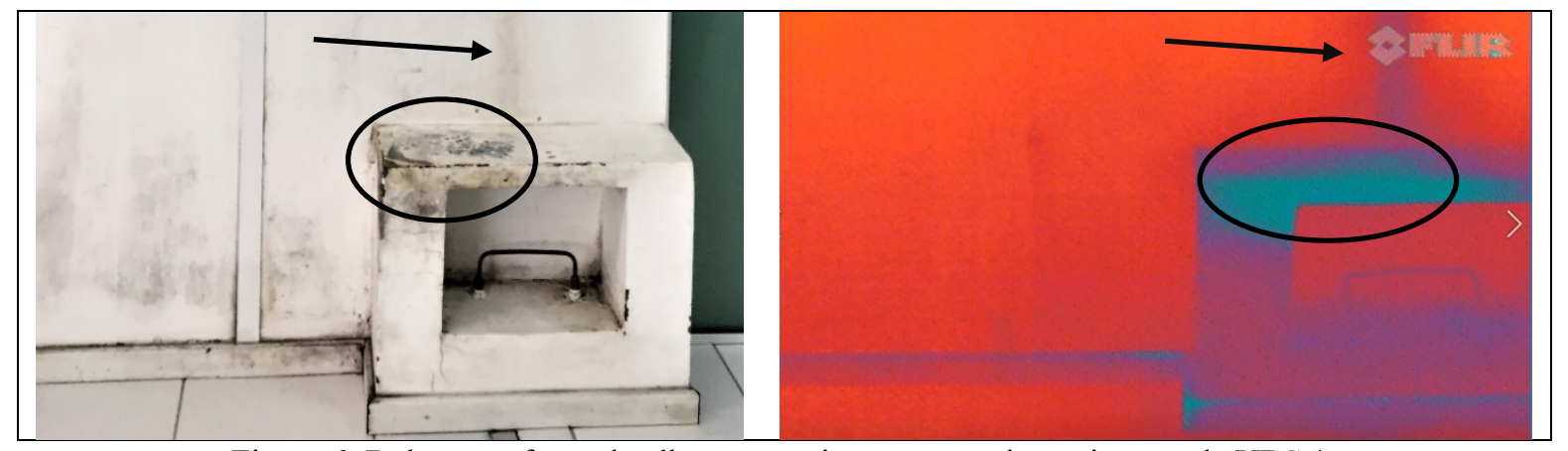

Figura 6: Bolor e mofo no detalhe construtivo no segundo pavimento da UBS 1.

Na inspeção visual e fotográfica sem o uso da câmera térmica, não era possível identificar umidade também no teto. Com o uso da câmera térmica foi encontrado acúmulo de água, indicada na Figura 7, decorrente do problema de infiltrações na junta de dilatação e consequente infiltração de água na parede (Figura 6).

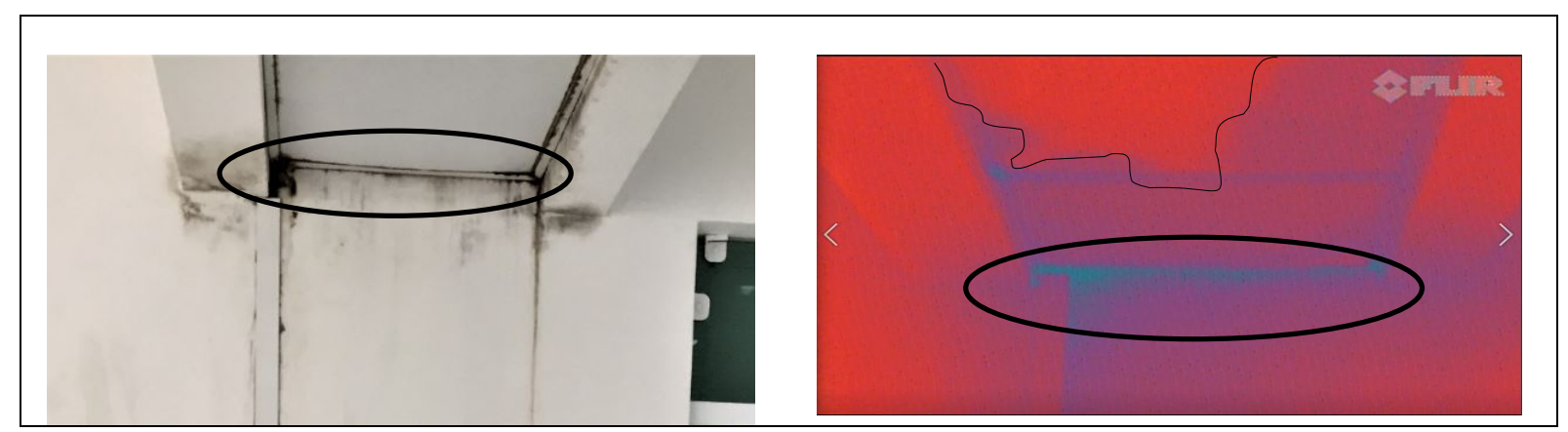

Figura 7: Bolor/mofo e umidade no rebaixamento de teto do segundo pavimento

Nas demais UBS, as imagens termográficas evidenciavam as manifestações já discutidas anteriormente, mas, não se encontrou nenhuma manifestação não anteriormente identificada por meio da imagem digital. 


\section{DISCUSSÃO DOS RESULTADOS}

De forma geral, a manifestação patológica menos recorrente nas UBS avaliadas foram as eflorescências. Nas Figuras 8 a 11, foi possível avaliar a incidência de cada manifestação em todas as UBS avaliadas.

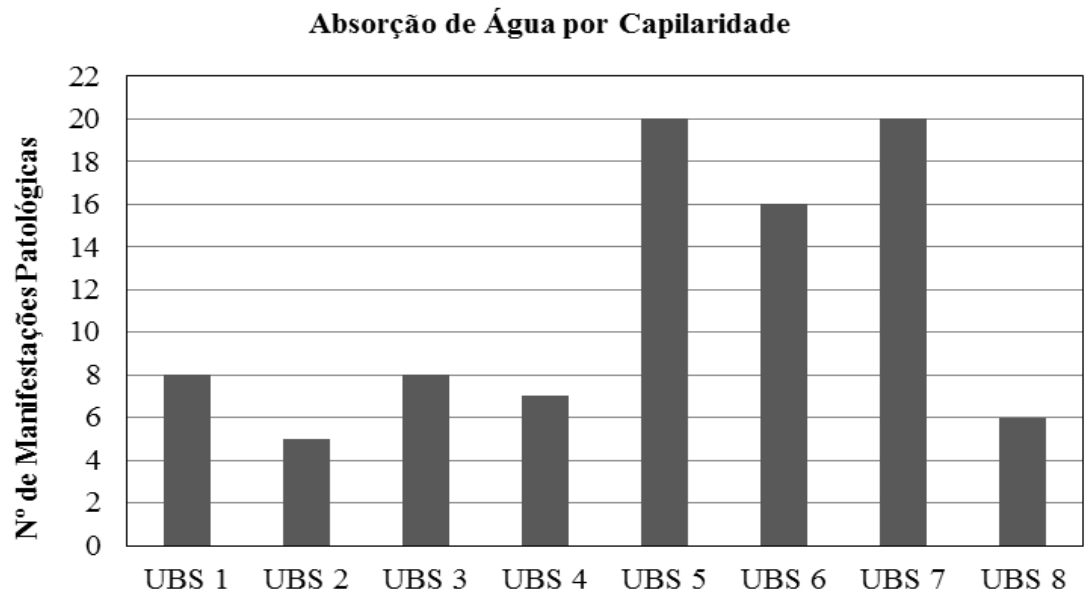

Figura 8: Quantificação por aparecimento da manifestação de infiltração de água nas edificações por capilaridade.

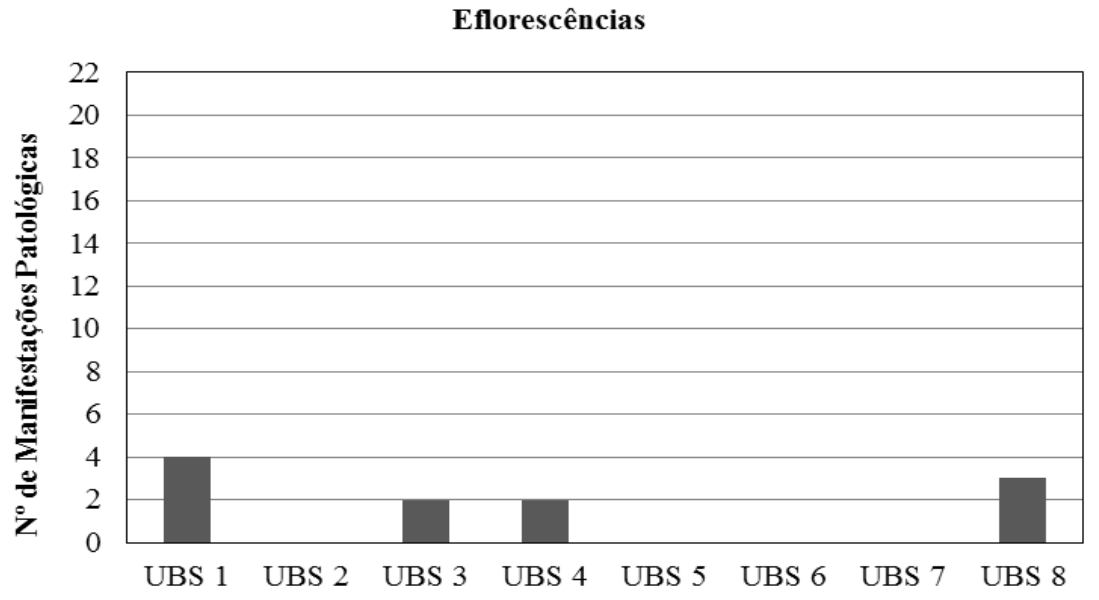

Figura 9: Quantificação, por aparecimento, das eflorescências nas UBS analisadas.

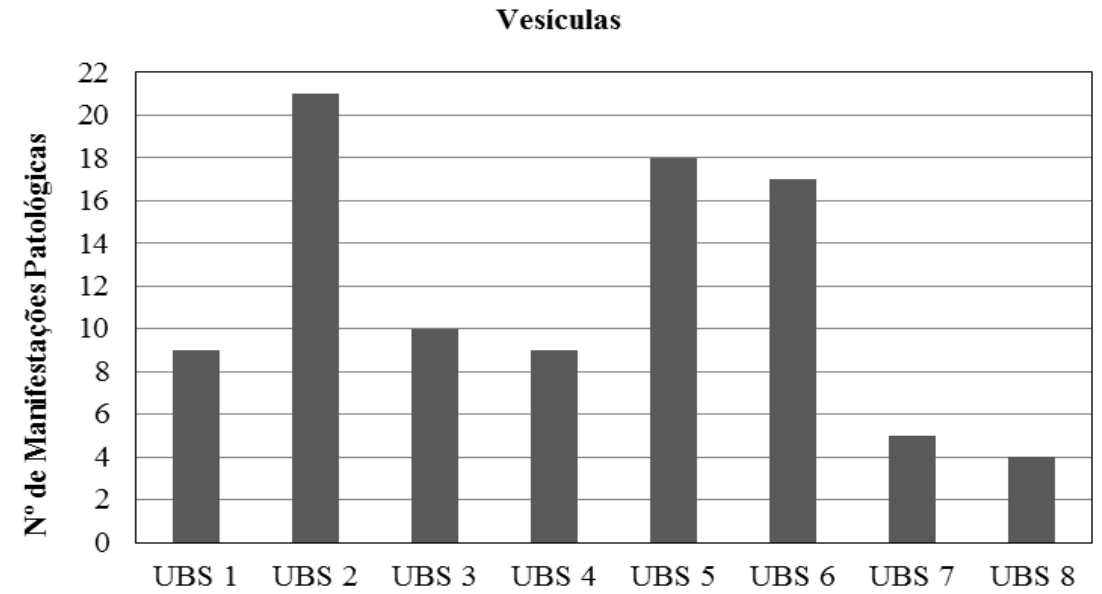

Figura 10: Quantificação, por aparecimento, de vesículas, causadas por presença de umidade nas UBS analisadas. 


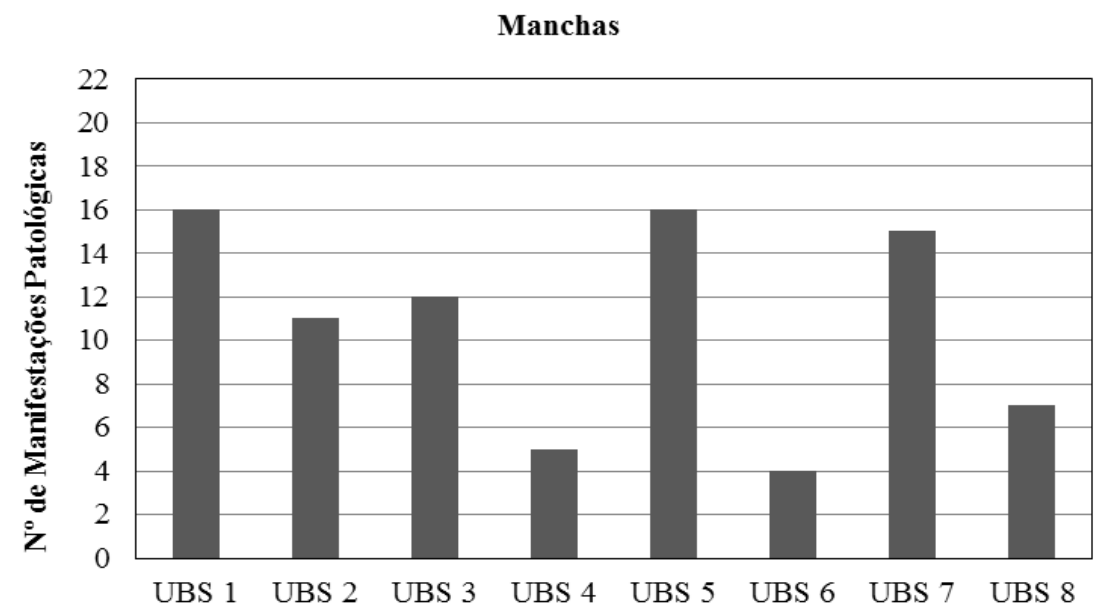

Figura 11: Quantificação, por aparecimento, de manchas, causadas por presença de umidade nas UBS analisadas.

Na Figura 12, foi determinada a participação de cada manifestação (vesículas, eflorescência, absorção de água por capilaridade e manchas) em todas as oito UBS avaliadas. Verificou-se que exceto as eflorescências, as demais manifestações patológicas avaliadas apresentaram incidência semelhante, de forma quantitativa, nas UBS do município.

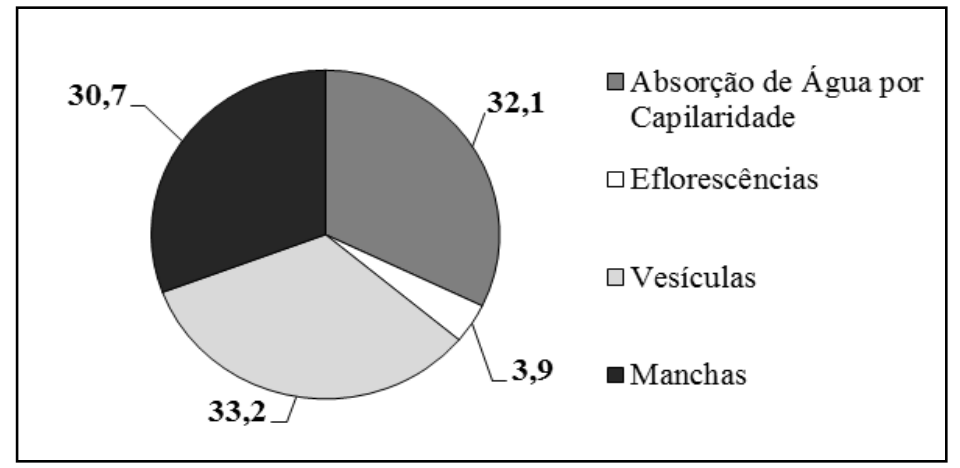

Figura 12: Quantificação, por aparecimento, de todas as manifestações avaliadas causadas por presença de umidade nas UBS analisadas.

Com isso percebeu-se que o grande problema das ocorrências das manifestações foi a má qualidade dos serviços executados e a falta de manutenção dos edifícios. Compreendendo os teores de participação de cada tipo de manifestação patológica caudada pela umidade, o principal serviço de engenharia corresponde em fazer uma grande reforma, executando, principalmente, serviços de impermeabilizações nas coberturas e vigas baldrames. No segundo momento seria necessário fazer a recuperação dos revestimentos argamassados das unidades básicas de saúde que apresentam perda de desempenho e de integridade, devido às manifestações provenientes da umidade.

\section{CONCLUSÕES}

A finalidade principal deste estudo foi avaliar e demostrar a existência das atividades de manifestação patológica nas edificações das unidades básicas de saúde pública, de um município do estado de Santa Catarina (Brasil), localizado a 72 $\mathrm{km}$ da capital, Florianópolis.

Verificou-se uma grande ocorrência de problemas nas edificações analisadas devido às falhas de projeto, execução e principalmente de manutenção, afetando diretamente o desempenho dos locais. Constatou-se que as manifestações patológicas existem em todas as edificações aqui vistoriadas, com diferentes idades.

Os revestimentos argamassados e pinturas são sistemas que apresentam maior quantidade de problemas. As infiltrações por água de precipitação, ascensão de água do solo por capilaridade e a falta de circulação de ar entre os ambientes despontaram como a principal fonte das manifestações patológicas na maioria dos locais avaliados. 
A grande quantidade de manifestações patológicas identificadas e de edificações avaliadas inviabiliza a análise individualizada das falhas existentes. Dessa forma, optou-se somente pela citação das manifestações patológicas de maior relevância e com maior incidência nos locais das edificações selecionadas para este trabalho.

A Secretaria da Saúde e UBS (Unidade Básica de Saúde) demonstraram terem muitas deficiências em relação à prevenção de manifestações patológicas de umidade, apresentando problemas de impermeabilização em vigas baldrame, falta de manutenção da impermeabilização em telhados e lajes de cobertura, ineficiência na execução de peitoris de granito nas janelas, além da falta de proteção adequada em platibandas, como rufos ou peitoris de revestimentos cerâmicos.

Com muita importância também e em grande intensidade nas edificações estudadas, aparecem as manifestações de mofo, bolores e fungos, devido a uma série de fatores, mas principalmente a falta de circulação de ar e a constante umidade nos elementos construtivos. O mofo em contato direto com os pacientes, pode gerar novas doenças ou dificultar as suas recuperações.

Salienta-se que a prevenção nestes casos, torna-se a mais adequada ação para gerar novas e recorrentes reformas ou manutenções. O plano de ação mais apropriado nestas edificações tornou-se os serviços de impermeabilização que deverá ser adequado para cada ambiente e para cada elemento construtivo.

\section{REFERÊNCIAS}

ASSOCIAÇÃO BRASILEIRA DE NORMAS TÉCNICAS. NBR 15575-1: Edificações Habitacionais - Desempenho Parte 1: Requisitos gerais. Rio de Janeiro, 2013.

ALUCCI, M. P. et al. Bolor em Edifícios: causas e recomendações. In: IPT- Instituto de Pesquisas Tecnológicas do estado de São Paulo. Tecnologia das Edificações. São Paulo: PINI, 1988.

ALUCCI, M.P.; FLAUZINO, W.D.; MILANO, S. Bolor em edifícios: causas e recomendações. In: Tecnologia de edificações. Coletânea de trabalhos da Divisão de Edificações do Instituto de Pesquisas Tecnológicas. Editora Pini, São Paulo, 1988.

ALVES, C.E.A. Construção em aço no Vale do Aço do Estado de Minas Gerais. 2011. 177 f. Dissertação(Mestrado em Engenharia Civil). UFOP, Ouro Preto, 2011.

BARROS, M. M. S. B.; SABBATINI, F. H. Recomendações para execução de revestimento de argamassa para paredes de vedação internas e exteriores e tetos. São Paulo, 2001.

CAMPANTE, E. F.; BAÍA, L. L. M. Projeto e execução de revestimento cerâmico. São Paulo: O Nome da Rosa, 2003.

CARUANA, C.; GRIMA, C.; YOUSIF, C.; BUHAGIAR, S.; CURMI, R. Overview of testing methodologies for thermally improved hollow-core concrete blocks. Energy Procedia, 62, 180-189. 2014.

CICHINELLI, Gisele. Patologias cerâmicas: Porque ocorrem os desplacamentos e trincas em edificações revestidas com cerâmicas e quais as recomendações dos especialistas para evitar problemas. Revista Téchne - A revista do engenheiro civil, [s. 1.], n. 116, p. 44-50, nov. 2006.

CINCOTTO, M. A. Estudo da composição química da cal hidratada produzida no Estado de São Paulo. Dissertação (Mestrado). Escola Politécnica da USP, São Paulo. 1977. 57p.

DAL MOLIN, D. C. C. Fissuras em estruturas de concreto armado: análise das manifestações típicas e levantamento de casos ocorridos no estado do Rio Grande do Sul. Dissertação (Mestrado em Engenharia) - Pós-Graduação em Engenharia Civil, Universidade Federal do Rio Grande do Sul, Porto Alegre, 1988.

FRANÇA, A. V. et al. Patologia das Construções: Uma especialidade na Engenharia Civil. Téchne, Curitiba, PR, p. 1-7, out., 2010.

GOOGLE EARTH. Disponível em: <https://www.google.com.br/earth/> . Acesso em: 20 maio 2019. 
JUNGINGER, M.; MEDEIROS, J. Rejuntamento de revestimentos cerâmicos: Influência das Juntas de Assentamento na Estabilidade de Painéis. 2004. 154 f. Dissertação (Mestrado em Engenharia Civil) - Universidade de São Paulo, São Paulo, SP, 2004.

LICHTENSTEIN, Norberto B. Boletim técnico 06/86: Patologia das Construções. São Paulo: Escola Politécnica da Universidade de São Paulo, 1985.

MONTECIELO, J.; EDLER, M. Patologias Ocasionadas Pela Umidade nas Edificações. Patologias Ocasionadas Pela Umidade nas Edificações, Cruz Alta, RS, p. 1-10, jul., 2016.

PEREZ, A. R. Umidade nas Edificações: recomendações para a prevenção de penetração de água pelas fachadas. Estado de São Paulo, SP, 1988.

PINTO, J. A. N. Patologias de impermeabilização. Santa Maria: Multipress, 1996.

ROSCOE, M. T. Patologias em Revestimento Cerâmico de Fachada. Belo Horizonte: Escola de Engenharia da UFMG, 2008.

SILVA. A. F. Manifestações patológicas em fachadas com revestimento argamassado: Estudo de caso em edifícios em Florianópolis. 2007. 190 f. Dissertação (Mestrado Arquitetura e Urbanismo) - Departamento de Arquitetura e urbanismo, Universidade Federal de Santa Catarina, Florianópolis, 2007.

SILVA, K. B. A. Patologias em edificações na cidade de Campina Grande e da necessidade de legislação preventiva e eficaz. 2010. 94 f. Dissertação (Pós-Graduação em Engenharia Civil) - Universidade Federal de Campina Grande, 2010.

SILVA, M. G.; TISCOSKI, L. P. Levantamento de problemas patológicos ocorridos no estado de Santa Catarina. 1999. 55 f. Trabalho de Conclusão de Curso (Engenheira Civil) - Universidade Federam de Santa Catarina, Florianópolis, SC, 1999.

SOUZA, M. F. de. Patologias Causadas pela Umidade nas Edificações. 2008. 64 f. Monografia (Especialização em Construção Civil) - Escola de Engenharia, Universidade Federal de Minas Gerais, Belo Horizonte, 2008.

SOUZA, M. V.; RIPPER, T. Patologia, recuperação e reforço de estruturas de concreto. 1 ed. São Paulo: Pini, 1998.

SOUZA, V. C. M.; RIPPER, T. Patologia, recuperação e reforço de estruturas de concreto. 1. ed. São Paulo: Pini Ltda, 2009.

THOMAZ, Ercio. Trincas em Edifícios: Causas, prevenção e recuperação. Editora PINI, 1989.

UEMOTO, K. L. Patologia: Danos causados por eflorescência. Tecnologia de Edificações. Coletânea de trabalhos da Div. de Edificações do IPT. São Paulo: Pini, IPT - Instituto de Pesquisas Tecnológicas do Estado de São Paulo, 1988. p. 561564.

VERÇOZA, E. J. Patologia das Edificações. Porto Alegre: Editora Sagra, 1991. 